O MITO DA MATIN PERERA DE TAPERAÇU CAI E O CONCEITO DE DÁD APROXIMANDO-SE DE

CONCEITO ANTROPOLÓG 


\section{O MITO DA MATINTA PERERA DE TAPERAÇU CAMPO E O CONCEITO DE DÁDIVA: APROXIMANDO-SE DE UM CONCEITO ANTROPOLÓGICO}

\section{FERNANDO ALVES DA SILVA JÚNIOR}

UNIVERSIDADE FEDERAL DO PARÁ, BRAGANÇA/PA, BRASIL 


\title{
O MITO DA MATINTA PERERA DE TAPERAÇU CAMPO E O CONCEITO DE DÁDIVA: APROXIMANDO-SE DE UM CONCEI- TO ANTROPOLÓGICO
}

\author{
Resumo \\ O plano deste artigo tem por objetivo aproximar as narrativas orais so- \\ bre a Matinta Perera da comunidade bragantina de Taperaçu Campo ao \\ conceito de dádiva de Marcel Mauss (2003), considerando a pesquisa \\ desenvolvida nessa localidade no decorrer dos anos de 2012 e 2013. \\ Para tanto, utilizaremos os conceitos de Mauss de que há nas relações \\ sociais a tripla obrigação: a de dar, de receber e de retribuir, além disso, \\ aproximaremos essa observação à oferta que se faz a Matinta que, via \\ de regra, são o tabaco, o café ou o peixe. O procedimento metodológico \\ está pautado nas pesquisas de campo para o registro das narrativas que \\ perpassaram pela gravação com alguns moradores e, consequentemente, \\ a transcrição dos textos orais que, por fim, foram comparados à teoria \\ da dádiva de Mauss. Preliminarmente, concluiu-se que a abnegação dos \\ moradores locais em oferecer a essa divindade amazônica, de um lado, \\ sugere uma ação altruísta e, por outro, corresponde a uma ação egoísta, \\ já que eles dão (tabaco, café etc), pensando em receber (acalanto, não \\ agouro etc.). A importância deste trabalho para os estudos antropoló- \\ gicos está na aproximação da crendice popular, calcada na expressão da \\ literatura popular, e da sociologia-antropologia, como outra forma de \\ abordar e cotejar as narrativas orais bragantinas. \\ Palavras-chave: Dádiva, Matinta Perera, narrativas orais, Taperaçu \\ Campo.
}

\section{THE MYTH OF MATINTA PERERA OF TAPERAÇU CAMPO AND THE CONCEPT OF GIFT: APPROACHING OF AN AN- THROPOLOGICAL CONCEPT}

\begin{abstract}
The work plan of this article aims to approximate the oral narratives about Matinta Perera of Bragança community Taperaçu Campo to the concept of gift by Marcel Mauss (2003), considering the research developed in this community over the years 2012 and 2013. To do so, we use the concepts of that Mauss's social relations triple duty: that of giving, receiving and giving back, will approach this observation that the offer is made to matinta that, as a rule, is tobacco, coffee or fish. The methodological approach is based in the research field to record the narratives that permeated the recording with some locals and hence transcription of oral texts, which were finally compared to the theory of giving Mauss. Preliminarily, it was concluded that the denial of the locals in this Amazon offer divinity on the one hand, suggests an altruis-
\end{abstract}


tic action, and the other corresponds to a selfish action, since they give (tobacco, coffee etc.) considering receive (lullaby, not foreboding, etc.). The importance of this anthropological study studies is to approach the popular belief, grounded in this expression of popular literature, to sociology-anthropology as another way to approach and collate bragantinas oral narratives.

Keywords: Gift, Matinta Perera, oral narratives, Taperaçu Campo.

\section{LE MYTHE DE LA MATINTA PERERA DE TAPERAÇU CAMPO ET LA NOTION DE DON: L'APPROCHE D'UN CONCEPT AN- THROPOLOGIQUE}

\section{Résumé}

Le plan de cet article vise à rapprocher les récits oraux sur Matinta Perera de la communauté de Taperaçu Campo à la notion de don Marcel Mauss (2003), compte tenu de la recherche développée dans cette communauté au cours des années 2012 et 2013. Tant à, nous utilisons les concepts de relations sociales triple devoir que Mauss: donner, recevoir et rendre, abordera cette observation à offrir qui fait matinta que, en règle générale, est le tabac, le café ou poissons. L'approche méthodologique est basée dans le domaine de la recherche pour enregistrer les récits qui imprégnait l'enregistrement avec des gens du coin et donc la transcription de textes oraux, qui ont finalement été comparées à la théorie de donner Mauss. Préliminaire, il a été conclu que le refus des habitants de cette divinité Amazon offre d'une part, suggère une action altruiste, et l'autre correspond à une action égoïste, car ils donnent (tabac, café etc.) Considérant recevoir (berceuse, aucun présage, etc.). L'importance de cette étude pour la recherche anthropologique est plus proche à la croyance populaire, la terre dans cette expression de la littérature populaire, la sociologie, l'anthropologie comme une autre façon d'aborder et de rassembler bragantinas récits oraux.

Mots-clés: Don, Matinta Perera, récits oraux, Taperaçu Campo.

Endereço do autor para correspondência: Rua Zacarias Correa, n 1162 , bairro Padre Luiz Freire, Bragança/PA, CEP 68600-000. E-mail: macuninfeta@gmail.com 
PRIMEIROS PASSOS DA PESQUISA DE CAMPO

Este trabalho corresponde a uma parte da dissertação apresentada ao Programa de Pós-Graduação em Linguagens e Saberes na Amazônia (PPGLS) da Universidade Federal do Pará (UFPA), cujo objetivo consistiu em analisar as narrativas orais acerca do mito da $\mathrm{Ma}$ tinta Perera na comunidade de Taperaçu Campo, localizada nos campos bragantinos (PA), mediante gravação de textos orais.

Para o registro das narrativas, utilizei um gravador digital com microfone, contudo, houve casos em que dispensei o uso do aparelho e as conversas foram somente anotadas em uma agenda, momento em que a informalidade do encontro dispensava seu uso.

Minha primeira experiência com as narrativas orais míticas bragantinas foi com o desenvolvimento do projeto de conclusão do curso de Especialização em Linguagens e Culturas na Amazônia ${ }^{1}$, ofertado pela UFPA no decorrer do ano de 2011, no qual pude entrevistar e analisar as narrativas orais míticas de dona Josefa Silva, moradora da comunidade de São Domingos, Bragança (PA). Essa pesquisa deu início ao projeto acerca da narrativa sobre a Matinta Perera por uma simples questão: quase todos os narradores pesquisados desde o ano de 2011 citaram histórias acerca dessa bruxa amazônica² ${ }^{2}$

Quando iniciei a pesquisa para o PPGLS, o objetivo era analisar as narrativas orais da Matinta Perera nos arredores de Bragança, porém, a impossibilidade do projeto restringiu o espaço de pesquisa, como esperávamos, o recorte espacial recaiu sobre a comunidade de Taperaçu Campo, em virtude de uma pessoa, dona Edilene. Não tinha intimidade com a comunidade até conversar com essa senhora acerca do meu trabalho e ela me convidar para gravar com seu pai, Raimundo Silva de Aviz. A partir de então, gravei com nove moradores de Taperaçu Campo (Maria Silva Aviz, Raimundo Silva de Aviz, Agostinho da Silva Sousa, Aldenor Cirilo, Enedina de Sousa, João Coelho de Sousa, Orivaldo Pereira da Silva, Egídio Ferreira da Silva, Arlindo Araújo e Manoel de Jesus), todos indicados e convidados por dona Edilene, uns na casa de minha guia e outros em suas próprias residências.

Quanto à técnica de pesquisa, convém mencionar que a orientação metodológica das primeiras visitas em 2011, quando iniciei minha pesquisa de campo na comunidade de São Domingos com dona Josefa Sousa, consistia em fazer um primeiro contato para explicar a intenção da pesquisa e agendar a gravação para um momento mais cômodo para a entrevistada. Contudo, quando eu mencionava o objeto da pesquisa (as narrativas acerca de Matinta Perera, de labisonho etc), os narradores logo iniciavam suas falas me contando subitamente o que eles conheciam, resultando em perda de alguns detalhes para meu trabalho. Quando chegava para a segunda visita, com gravador e máquina fotográfica, aquelas histórias e a espontaneidade do momento anterior se esmaeciam em uma narrativa que não repetia a anterior. Eis o aspec- 
to singular de cada entrevista (Alberti 2005:105).

Diante desse impasse metodológico, alterei meu modo de abordagem e comecei a adequar a forma de fazer pesquisa de campo de acordo com cada encontro, deixei o gravador ligado desde a chegada até a partida e, no meio da conversa, explicava o objetivo do trabalho. Essa proposta não foi totalmente segura, já que também gerou perda de informação, por exemplo, na entrevista com seu Aldenor Cirilo, que me foi apresentado por dona Edilene na noite do dia 30 de dezembro de 2012, quando ela acabou de explicar o motivo da minha visita, o senhor iniciou a sua narrativa e, por pouco, não perco as informações que buscava.

$\mathrm{Na}$ primeira visita com dona Josefa Sousa, não consegui gravar uma informação que ela não me explicou novamente, o caso de pessoas que contam histórias de dia criarem rabo, interdição esta também relatada por Cascudo (1978). No final das conversas, explicava que aquilo que fora gravado seria utilizado somente com a permissão do narrador e que a finalidade seria a produção dos trabalhos acadêmicos.

O incômodo no momento das entrevistas foi a luz vermelha do gravador digital indicando o rec, que suprimi com uma fita adesiva preta justamente por conta da intimidação que, a meu ver, causava nos entrevistados. A distância que eu mantinha com os narradores foi a mais natural possível, uma vez que o uso de um microfone digital garantiu uma gravação audível ${ }^{3}$ sem a necessidade de aproximar, desagra- davelmente, o gravador das bocas de nossos anfitriões.

As entrevistas não tiveram um roteiro pré-definido, com perguntas que requeriam respostas objetivamente explicativas. Elas seguiram a dinâmica de uma conversa, no entanto, o direcionamento era muito bem delimitado: as histórias da Matinta Perera.

Não esperava que essas histórias tivessem ocorrido somente em Taperaçu Campo, ansiava por encontrar as narrativas que fizessem parte do acervo que circulava oralmente pela comunidade. Em algumas visitas, logo que esgotavam as narrativas da Matinta Perera, surgiam outros casos de aparições e encontros inesperados. Assim identifiquei as narrativas míticas que transitam livremente na comunidade: a narrativa do bode, a do Gritador, a do fogo do campo, a da Mãe d'Água, a da Curupira, a do Ataíde, a do Labisonho e a da Matinta Perera.

À medida que eu registrava as histórias da Matinta Perera e o conhecimento acerca dessa personagem, em sua grande maioria feminina, se aprofundava, tentei garantir a impessoalidade nas entrevistas, não fornecendo detalhes da personagem (pedido de tabaco, de café, a possibilidade de prendê-la etc), sempre esperava os narradores finalizarem suas histórias para, então, perguntar os detalhes não ditos. Como o objetivo era garantir a descontração durante as conversas, eu também contava minhas histórias, percebi que isso os motivava a narrar outras. Pensava sempre em conhecer o máximo de narrativas possíveis de cada anfitrião. 
$\mathrm{Na}$ segunda visita à casa de seu Raimundo de Aviz, no final da tarde do dia 16 de setembro de 2012, interessado na história da mulher que se transforma em onça, pois ouvira dona Josefa Sousa e dona Maria de Aviz contá-la, perguntei a seu Raimundo se conhecia tal história, ele me disse que não. Resolvi reproduzir o caso contado por dona Josefa. Após escutar a minha versão, ele se lembrou de outra similar e me narrou. Aprendi essa "técnica" com Agnelo Melo $\mathrm{Neto}^{4}$, antes de ele me levar pelos caminhos capilares do Montenegro à procura dos narradores. Dizia ele que era preciso dois ou mais contadores para que as histórias fossem lembradas.

\section{A COMUNIDADE TAPERAÇU CAMPO}

Taperaçu Campo compõe um grupo de comunidades que formam parte da região dos campos bragantinos pertencentes a Reserva Extrativista Marinha
Caeté-Taperaçu. A comunidade é largamente conhecida como Acarpará, nome que de acordo com seu Egídio Ferreira da Silva (Taperaçu Campo, 20 de julho de 2013) surgiu por conta da iniciativa de uma associação que foi criada em meados da década de 60 para fortalecer a agricultura local, especialmente com o cultivo do feijão caupi, a chamada Associação de Crédito Rural do Pará (ACARPARÁ).

A denominação Taperaçu Campo abrange atualmente as seguintes comunidades: Patalino, São Mateus, Acarpará, Porto dos Milagres e Porto da Mangueira. Essa divisão, como explicou seu Egídio, decorreu da atuação da Pastoral da Saúde quando precisou demarcar os grupos de trabalho e as áreas que seus agentes ocupariam. Alguns moradores, como o presidente da associação comunitária seu Arlindo Araújo, insistem em denominar todo esse espaço como Taperaçu Campo, da forma como é escrito nos documentos oficiais (conta de energia, por exemplo).

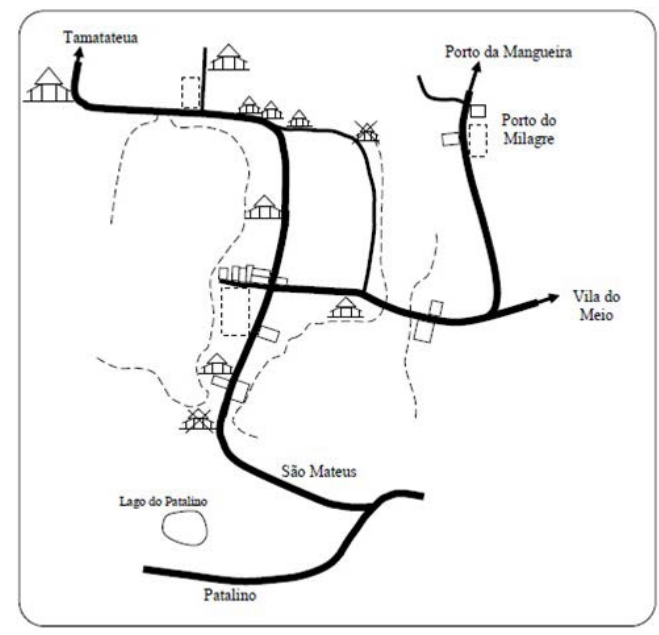

Figura 1 - Mapa da comunidade Taperaçu Campo. Projeto gráfico de Fernando Alves (2013). 
A comunidade possui duas escolas (uma municipal de ensino fundamental e outra estadual de ensino médio), uma igreja católica (a do Sagrado Coração de Jesus), um posto de saúde, três campos de futebol (na entrada da comunidade do Patalino, em frente à igreja e ao posto de saúde e outro na comunidade do Porto dos Milagres) e dez olarias. Além das olarias que empregam boa parte da comunidade, outras fontes de renda são o pescado e a agricultura.

O número substancial de olarias ${ }^{5}$ é resultado do grande número de matéria-prima (argila) encontrada nas regiões dos campos bragantinos. As olarias extraem a argila de suas propriedades e quando esgotam os recursos de seus limites pagam para retirarem o material das propriedades dos demais moradores: dragam os campos com tratores e deixam somente locais esburacados. Dona Edilene explicou que alguns moradores aproveitam essas covas produzidas pela dragagem como "tanques naturais" para armazenamento da água das chuvas, no verão, esses reservatórios são utilizados para amolecer mandioca antes do preparo do subproduto: a farinha.

\section{ESBOÇANDO UM MITO: A MATIN- TA PERERA}

A Matinta Perera é, via de regra, uma senhora idosa em condições de se metamorfosear em uma espécie de pássaro de hábitos noturnos e transitar pela comunidade. $\mathrm{O}$ que marca a presença da Matinta é seu trinado: fiiite, fiiite, fiiite, Matiiinta Perera. Para a certeza do reconhecimento, é necessário identificar o nome da divindade em seu canto, aquilo que os moradores dizem que é a "dobração" do seu assobio, caso contrário, o apito noturno pode indicar a presença de outras entidades ${ }^{6}$ (a Curupira ou a Mãe d’Água) que emitem o mesmo assobio, com a diferença de não dobrarem o canto.

Neste trabalho, citarei de forma sintética as narrativas de seis moradores de Taperaçu Campo (Raimundo Silva e Agostinho da Silva Sousa, João Coelho de Sousa, Orivaldo Pereira da Silva, Egídio Ferreira da Silva, Arlindo Araújo) que relatam o momento da oferta a Matinta: tabaco, café e peixe que, mais adiante, articularei ao conceito maussiano de dádiva.

$\mathrm{Na}$ ordem de realização das entrevistas, a versão de seu Raimundo Silva de Aviz com seu Agostinho da Silva Sousa é a primeira a nos ensinar a maneira de capturar a Matinta Perera, ao convidá- la a buscar um cigarro ou a beber um pouco de café:

"A matintaperera, uma vez eu... a matintaperera é assim, ela passar pela sua casa, aí assobiar, aí você prender ela:

- Vem buscar um, um cigarro de manhã, vem busca uma, vem beber um café.

Ela fica, ela fica presa, ela só, ela só se acomoda quando ela... quando ela vai lá. Aí você dá aquela maniva, ela... Uma vez eu, eu fui... Ela pede $\mathrm{o}$, a pessoa vem pedir o cigarro, buscar, né? O tabaco? Eh, eh. Aí, tinha o cara que joga baralho acolá. Aí, quando foi umas duas horas chegou lá. Com um pouco mais 
chegou duas velhas, pano na cabeça. Elas tinham passado lá de noite, ele disse, ele gritou de lá onde eles estavam jogando baralho, disse:

- Vem buscar, vem buscar uma boia de peixe amanhã.

Foram simbora, assobiando, foram simbora. Quando foi essas horas, elas vieram.] [Raimundo: Foram bater lá?] [Augustinho: Vieram bater lá. Chegou lá, ele disse:

- Olha! Lá vem as mulher, vieram buscar o peixe.

Aí também foi pra lá, elas chegaram, ele foi pra lá dá a canga de peixe pra elas" (Raimundo Silva de Aviz, Agostinho da Silva Sousa, Taperaçu Campo, 16 de setembro de 2012).

Já para seu João Coelho de Sousa, uma maneira infalível para conhecer a identidade da Matinta Perera é oferecendo-lhe algo, o que tiver: café, tabaco, etc que uma pessoa aparecerá no dia seguinte cobrando o que fora prometido:

A matintaperera, a gente, ela dá o assobio dela, né? Aí se afinca uma faca encima da mesa ou, aí oferece o cigarro pra ela, pra ela tomar o café da manhã com você. Ganhar o cigarro. Aí quando é de manhã ela chega, aí você sabe quem é, uma pessoa.

(Mas ninguém fala nada, não?) Não, não, fala nada não. (Não precisa?) Fala nada não. Aí dá o café, só pra conhecer, só pra conhecer a pessoa. Porque a matintaperera é gente, não é bicho.

(...)

Mas você não sabe da matraca pra pegar ela, né? E quem sabe, aí ela dá o primeiro assobio você, pega a faca e [barulho de metal batendo em uma superfície de madeira], (Enfinca.) Enfinca na mesa. Aí dá o outro, você finca, dá o derradeiro, finca. Aí:

- Olha! De manhã vem tomar o café comigo.

Se tiver o café:

- Pode vir tomar o café comigo, cigarro. Vou ficar lhe esperando.

Quando é cedinho ela chega na sua porta. Aí você já conhece quem é. Mas porque é gente também. (Também é gente. Ela também não bate no pessoal, assim não?). Não, não, não, não, não bate não. A matintaperera não. Lá, ela acompanha, porque todo bicho acompanha pra meter o medo pra pessoa, pra ver se corre, né? Todo bicho acompanh". (João Coelho de Sousa, Taperaçu Campo, 12 de janeiro de 2013).

Para seu Orivaldo Pereira da Silva, o assobio que a matintaperera emite é sempre um pedido. $\mathrm{Na}$ sua história, protagonizada por seu avô, a matinta sempre seguia o senhor quando este partia para a maré pescar mero e todo o assobio que a "pai d'égua" emitia era um reclame do pescado que ele estava para conseguir:

(E a história do tabaco...) Agora do tabaco... (...que dão pra matinta, né?) ...o tabaco, o tabaco é a curupira, a a matintaperera (A matinta, né?) É. Porque uma vez, eu tenho o meu avô, ele pescava e foi, tava pescando, e tinha uma senhora que morava numa ilha (daqui, da praia?) Eh, eh. Ela virava. Quando foi um dia ele foi pra maré, passou a pai d'égua assobiou. 
- De manhã tu vem buscar um pedaço de mero.

(Mero? Ele ofereceu mero?) É. Porque ele pescava, pescava de mero.

- Vem buscar um pedaço de mero de manhã.

Quando foi de manhã cedinho que ele chegou da maré, ele olhou lá no meio do campo, tinha o campo, né? Ele olhou, lá vem, ele disse:

- Olha mulher! A mulher vem buscar o pedaço de mero.

(Já sabia) Já sabia. Chegou e disse:

- Ah seu Dico. Vim buscar um pedaço de mero que o senhor prometeu pra mim.

- Aaah! Era tu que tava assobiando, nera?

(E era conhecida?) Conhecida a velha lá. Ele agarrou tirou um pedaço de mero e deu pra ela. (Mas tem que dar, né?) Tem que dar. (Orivaldo Pereira da Silva, Taperaçu Campo, 12 de abril de 2013).

$\mathrm{Na}$ história de seu Egídio Ferreira da Silva, encontramos o momento exato em que a pessoa deve oferecer algo à matinta: "na dobração do assobio". $\mathrm{Na}$ sua narrativa, a Matinta era uma senhora que morava próximo à moça que promete o café, com o intuito de conhecer a identidade da velha. Ao divulgar para seus vizinhos a descoberta, irrita a velha Matinta que também é a curandeira da comunidade.

Olha, eles dizem, os mais antigos diziam que quando, aí ofereciam, né? Quando ela, ela, ela assobiava, quando eles esperavam na dobração do assobio. Eles diziam:

- Fiiite, matiinta...pe.
Quando ele chegava no perera aî eles negociavam:

- Vem buscar um pedaço de tabaco amanhã.

É. Então ali, bem aqui assim tinha uma velha, né? Mais aqui assim, uma velha antiga. E eles diziam que era ela, né? Aí uma vez, eu tinha um irmão que morava bem ali, o Romoaldo, e tinha a esposa dele, a Maria. E ela era cumadre da Maria, da minha cunhada, tá? (Uh, uh) Aí a Maria, nessa noite, ouviu o assobio e aí, ofereceu um pedaço de tabaco que quando foi de manhã a velha apareceu lá, apareceu. Aí ela não disse nada, deu o tabaco, não disse nada. Aí já contou pra outro, né? Então ela benzia, a velha benzia, (Mentira?) Eh, eh. (Ela era benzedeira?) Eh, eh, ela era benzedeira. Aí quando foi no outro, uns quatro dias aí contaram pra ela. Ela veio, ela veio. Chegou lá aí ela disse:

- Ah, comadre a, a minha filha tá com dor de cabeça, tá com febre, dê uma benzida nela aí.

Ela disse: [Emitindo voz de velho]: - É comadre, matintaperera não benze. (Egídio Ferreira da Silva, Taperaçu Campo, 20 de julho de 2013).

Por fim, temos a versão de seu Arlindo Araújo que confirma as anteriores quanto ao fato do oferecimento sinalizar uma visita na manhã seguinte. A Matinta Perera emite seu trinado, o morador oferece o café ou o tabaco e na manhã sucede o "encontro" com uma pessoa que virá requisitar o prometido.

"(E a matinta, ela mexe com o pessoal também?) A matinta, a matinta 
não, a matinta, ela só faz o coisa de ficar assobiando ali. Que tem uma que avoa, isso é história que eles contam, eu nunca vi. (E ninguém oferece pra ela? $\mathrm{O}$ pessoal diz que...) É, eles ofereciam, é tem gente que conta aí que ofereciam cigarro, tabaco ofereciam alguma coisa, quando era de manhã cedinho, diz que chegava uma pessoa lá na porta. (Pedindo, certinho?) Certinho" (Arlindo Araújo, Taperaçu Campo, 31 de agosto de 2013).

São cinco conversas que se ligam por um fio comum, o oferecimento. São duas configurações da Matinta Perera: a ornitomórfica, quando a entidade se apresenta no tempo noturno, emitindo seu assobio que pode ser interpretado como um pedido; e a antropomórfica, momento em que a pessoa que se transforma em ave surge para requerer o prometido da véspera.

\section{BREVE OBSERVAÇÃO ACERCA DA DÁDIVA}

Para Mauss (2003:193), o potlatch, nome chinook utilizado de Vancouver ao Alaska, significa "nutrir" ou "consumir". Mais propriamente "rivalizar com presentes", as regras implícitas nesse jogo são aquelas que "obriga[m] a retribuir o presente recebido". Dois elementos basilares são encontrados em Samoa (Polinésia): "o da honra, do prestígio, do mana que a riqueza confere, e o da obrigação absoluta de retribuir as dádivas sob pena de perder esse mana, essa autoridade, esse talismã e essa fonte de riqueza que é a própria autoridade" (Mauss 2003:195, grifo do autor).
Aqui, refletimos acerca da hierarquia colocada por Caillé (1998) na superioridade das divindades em frete ao sujeito comum. As formas de relacionamento a partir do regalo que é entregue à Matinta Perera pode, em certa medida, contribuir para a compreensão de que a leitura da dádiva colocaria esse jogo hierárquico em seu sentido inverso, uma vez que o morador que se sente coagido em oferecer, a partir do momento que dá, retoma para si a posição hierarquicamente superior àquele que recebeu, criando a relação de débito.

A base dessa relação de troca está no taonga: "tudo o que é propriedade propriamente dita, tudo o que pode ser trocado" (Mauss 2003:196), ele é fortemente ligado à pessoa que o possui, é o hau, "espírito das coisas" (Mauss 2003:197). A coisa dada, obrigatoriamente recebida, deve circular, a coisa recebida que vira coisa dada a propósito do hau (espírito) que ela possui.

Não pode inexistir retribuição, caso aconteça de uma coisa recebida não ter um substituto que a mantenha circulando "poderia advir um mal" quiçá a morte (Mauss 2003:198). Nesse sentido, "você me dá um, eu dou a um terceiro, este me retribui um outro, porque ele é movido pelo hau de minha dádiva; e sou obrigado a dar-lhe essa coisa, porque devo devolver-lhe o que em realidade é o produto do hau de seu taonga" (Mauss 2003:198). Neste caso, a coisa dada conserva em si algo que é do doador. A dádiva é a metonímia das relações sociais, toma-se uma parte (café, ta- 
baco e peixe) pelo todo (a pessoa moral que recusa de si).

Mauss (2003) afirma que essa coisa dada está entranhada por uma alma (hau), senão a do próprio doador, ela assume a alma do primeiro dono, ela é alma também e, sobretudo, necessita retornar para seu lar de origem. Se não for constantemente repassada, o detentor corre o risco de receber um grande mal sobre si. A Matinta que recebe a alma daquele que ofertou, recebe o outro na medida em que a coisa dada (café, tabaco ou peixe) não é simples coisa, mas símbolo de uma relação com o outro; recusar a oferta é recusar a pessoa moral que a oferta, não se recusa simplesmente a coisa dada, o que se recusa é o própria pessoa que se entrega naquele ato de doar algo de si que é si mesmo.

Assim, Mauss (2003:201-202) propõe três instâncias da dádiva: a obrigação de dar, a obrigação de receber e a obrigação de retribuir. Isso porque "a prestação total não implica somente a obrigação de retribuir os presentes recebidos, mas supõe duas outras igualmente importantes: obrigação de dar, de um lado, obrigação de receber de outro". Negar uma dessas três instâncias "equivale a declarar guerra, é recusar a aliança e a comunhão". É nesse sentido que a dádiva assume o conceito de crédito, na medida em que o objeto dado retorna com valores outros agregados a ele. Para que os bens circulem dentro da comunidade, há a necessidade do indivíduo ser, em certo grau, perdulário.

\section{PENSANDO A DÁDIVA NO MITO DA MATINTA PERERA}

Nota-se que o oferecimento postula uma relação que abarca o envolvimento de um ente superior com um sujeito local que dá, de um lado, enquanto o donatário, por outro, torna-se um semelhante quando transforma-se em gente para se revelar como um conhecido no momento do "fechamento" do contrato assumido entre eles.

Observa-se nesse momento das narrativas que o conceito de sacrifício ${ }^{7}$ se reveste daquele espírito definido pela dádiva maussiana na medida em que esse objeto da troca (café, tabaco e peixe) ganha ares de obrigação, o que é explicado por Mauss (2003:198) ao afirmar "que a coisa recebida não é inerte. Mesmo abandonada pelo doador, ela ainda conserva algo dele", considerando-se que "o vínculo de direito, vínculo pelas coisas, é um vínculo de almas, pois a própria coisa tem uma alma, é alma, [...] pois, aceitar alguma coisa de alguém é aceitar algo de sua essência espiritual, de sua alma" (Mauss 2003:200). Daí a obrigação de receber ser fundamental para o conceito de dádiva maussiano, não aceitar é recusar aquele que oferta, porque nega a comunhão com o vizinho e afrouxa os laços sociais na comunidade que os unem.

Assim, as três vertentes da teoria de Mauss acerca da dádiva circunscrevem-se na tripla obrigação de dar, de receber e de retribuir. Se a coisa dada conserva a essência daquele que ofertou se distanciando da coisificação do indivíduo (a alienabilidade) e tendendo para a humanização do objeto (a inalienabi- 
lidade), tal qual no sacrifício, o indivíduo não abnega por ser simplesmente perdulário, mas porque espera receber algo em troca, um altruísmo prenhe de egoísmo. Isso se evidencia a partir do momento em que a "prestação total não implica somente a obrigação de retribuir os presentes recebidos, mas supõe duas outras igualmente importantes: obrigação de dar, de um lado, obrigação de receber, de outro" (Mauss 2003:201). Para Lanna (2000:175), em um aspecto mais amplo, o conceito de dádiva de Mauss se espraia para além das relações econômicas, alcançando as ações de sociabilidade e cortesia entre as pessoas: a proposta geral do Ensaio é a liga social.

Nessa perspectiva pensada por Mauss (2003:201-202), a ação de reservar-se a não dar, que é proporcional a negar-se a receber, "equivale a declarar guerra; é recusar a aliança e a comunhão", o que justifica a intenção da Matinta em acompanhar um sujeito em Taperaçu Campo, quando nada é oferecido, resta a agressão física entre eles, pois, para se desvencilhar dos insistentes trinados da entidade, o sujeito aventura-se a capturá-la, lembrando-se da $\mathrm{Ma}$ tinta que foi "pega" com o tição de fogo da siribeira e ficou se batendo nas árvores até o "piedoso" sujeito libertá-la retirando o pedaço de siribeira do local que tinha enterrado. Isto mostra como ofensivo negar-lhe a amizade por conta do outro não ser merecedor de tal proximidade, aprofundando o distanciamento entre eles, tornando-se indiferente por manter a impessoalidade, negando-lhe essa relação de parentesco.
Em todo caso, não observamos a Matinta ausentar-se do compromisso de receber aquilo que foi dado e tão pouco o sujeito local negar a ela o objeto prometido. Em Taperaçu Campo, ela comparece a todos os encontros para tomar para si aquilo que lhe foi dado, para deixar evidente que o oferecedor, por seu turno, não se abstém de dar por pura "bondade", seu altruísmo reveste-se de egoísmo quando o café, o tabaco ou o peixe doado sinalizam uma vontade de conhecimento.

Quando na narrativa de seu Egídio Ferreira da Silva, a jovem senhora oferece tabaco à Matinta e descobre que sua vizinha transformava-se em ave visagenta, a dádiva repassada, em certa medida, leva algo da doadora, a Matinta leva um pouco do seu oferecedor e, quando a jovem revela o segredo da divindade, aquela dádiva retorna como algo negativo, pois a velha Matinta se nega, posteriormente, a benzer o filho da vizinha que estava adoentado.

São contratos que se estabelecem em Taperaçu Campo entre homens e divindades que buscam, sobretudo, amenidades. Não há troca apenas de alimentos por acalantos e ordem ${ }^{8}$, mas há busca por laços sociais conforme essas permutas são realizadas entre os moradores da comunidade: o vizinho que fornece café é o mesmo que receberá o peixe ou aquele que participava do beneficiamento do tabaco, na época em que este era fortemente cultivado na comunidade, a relação entre os vizinhos se expressa, também, por meio da troca, da saudação. 
Seu Augustino presta serviços para a família de seu Raimundo ordenhando as vacas e preparando o subproduto da mandioca, a farinha, na casa de forno do amigo com a mandioca cultivada pela família de seu Raimundo e colhida com a ajuda de seu Agostinho da Silva Sousa, os trabalhos, assim, envolvem as duas famílias. As atividades deste não são vistas como puro altruísmo, ele o faz porque granjeia para seu lado parte do leite que tira, tal qual da farinha que prepara, assim como dará para seu amigo Raimundo parte do pescado que trará da maré.

As relações sociais invadem a maneira de lidar com as aparições de Taperaçu Campo, a Matinta é uma pessoa da comunidade com a qual cotidianamente se irá relacionar, senão na mesma residência, como é o caso do filho curandeiro que rivaliza com a mãe também curandeira, quando ela se transforma em Matinta Perera e em égua, o mesmo caso do filho que surpreende a mãe Matinta transformada em passarinho (sururina) e descobre que se tratava da genitora somente quando esta chega a sua casa toda dolorida por conta das bordoadas que tomou do filho ao tentar fugir das pancadas dentro de casa, provavelmente encontrará um vizinho se transformando em Matinta ou labisonho em uma das olarias ou embaixo de alguma árvore nas noturnas e solitárias ruas da comunidade. A dádiva, em certa medida, explica essas relações de ida e volta das ações que se pratica na comunidade, mas também justifica a manutenção das amizades em Taperaçu Campo.
Em virtude de uma visita à casa de seu Agostinho da Silva Sousa, em 24 de janeiro de 2014, questionei acerca do funcionamento dos trabalhos comunitários em Taperaçu Campo, especialmente aquele voltado para o embarreamento das casas de taipa. De acordo com ele, a construção desse tipo de moradia era ${ }^{9}$, via de regra, responsabilidade do proprietário levantá-la com madeira geralmente extraída de mata próxima e coberta com palhas ou com telhas de fibrocimento onduladas ${ }^{10}$. Já no momento do embarreamento, outros homens da comunidade eram convidados a ajudarem o proprietário, momento da comunhão e do testar a força dos laços que os rodeiam. O embarreamento, que durava de um a dois dias, era regado à bebida alcóolica, geralmente destilada, fornecida pelo proprietário enquanto o almoço ficava a cargo da esposa do anfitrião, este último detalhe foi salientado pela esposa de seu Agostinho, dona Maria, que nos acompanhava na conversa.

O retorno de seu Agostinho aos colegas do mutirão do embarreamento era dado na ocasião em que outro membro da comunidade o requisitasse para serviço semelhante, se julgássemos que a retribuição de seu Agostinho alcançaria todos àqueles que embarrearam sua casa, chegaríamos à conclusão de que todo esforço empenhado em retribuir a ajuda dos vizinhos equiparou ou ultrapassou o necessário para ter embarreado sozinho sua residência sem a ajuda dos demais moradores, não obstante, um aspecto da vida comunitária de Taperaçu Campo esmaeceria o vínculo e a sociabilidade entre os indi- 
víduos, a aproximação e certo nível de altruísmo, ou seja, romperiam o nó que aperta as famílias.

Certo que não são todos os membros convidados, apenas aqueles que, de certa forma, aceitará o convite, porque quando se aceita, o dar-se pode ser o retribuir. Claro que ao convocado é reservado o direito de não comparecer, nestes termos a recusa não justificada, pode acarretar interpretações de que ele não necessitará do amigo em atividades futuras.

Esta exposição de seu Agostinho nos ajuda a compreender a postura da $\mathrm{Ma}$ tintaem requerer a "merenda", como diz se Manoel de Jesus, por meio do assobio. Não oferecer é acreditar que não precisará da Matinta, digo, do(a) vizinho(a) que se mostrará na manhã seguinte requerendo o prometido e, implicitamente, colocando-se a disposição do sacrificador-sacrificante, porque no fundo, como nos explicam Godbout (1992) e Caillé (2002), receber é se colocar como um doador em potencial, por isso, dar é, em certa medida, receber.

Nas observações feitas por Lanna (2000:175), se há algo que une as colocações de Mauss no Ensaio sobre a dádiva, essa é "a noção de 'aliança". Aquilo que se procura é um repouso com o ente que acompanha a pessoa para verificar as motivações que a faz correr: seria por conta do medo? Possivelmente. Mas tudo nos leva a crer que o morador oferece com a intenção de fortalecer essa liga social no dar e no receber, pois "o argumento central do Ensaio é de que a dádiva produz a aliança, tanto as alianças matrimoniais como as políticas, religiosas, econômicas, jurídicas e diplomáticas" (Lanna (2000:175).

Esse aspecto amplo do conceito de dádiva se espraia para além das relações econômicas, alcançando os aspectos de sociabilidade e cortesia entre os moradores, "mostra ainda como, universalmente, dar e retribuir, são obrigações, mas organizadas de modo particular em cada caso" (Lanna (2000:175). Os casos particulares, os locais ou momentos da doação interferem no retorno da dádiva; no seio da comunidade, o prestígio pode ser lido com base no círculo de amizade que se pretende construir entre os moradores, a jovem que deu tabaco à Matinta se liga à velha que se metamorfoseia por conta do interesse no tratamento xamânico da filha que adoecera; o movimento se dá na outra via com a Matinta de seu Orivaldo Pereira da Silva que se interessava pela amizade de seu Dico por conta do mero que ele pescava. Nesses termos, vale a colocação de Godbout (1992:11, 14) sobre o campo de atuação da dádiva que sobressai "o implícito e o não dito”, de sorte que a dádiva serve, sobremodo, "para estabelecer ligações”, ligações em certa medida pré-estabelecidas ou escolhidas de forma que o retorno seja certo.

Pensando a dádiva como um paradigma que se encontra no entremeio do individualismo e do holismo metodológico, Caillé (1998:10) parte do princípio de que, no primeiro, todos os cálculos nas relações sociais se direcionam para o interesse individual no cálculo egoísta de sempre ponderar 
as relações para nunca ter perdas, enquanto que, no pólo antagônico, todas as atenções se concentram no "costume, valores ou regras" que regem determinado grupo social, para o qual as ações nunca surpreendem porque são ditadas por regras que não serão rompidas, nesse caso "ninguém trairá" e, com isso, a responsabilidade de paridade ser completamente seguida.

No paradigma da dádiva, institui-se uma "aposta na aliança e na confiança”, aproximando essa leitura para nosso objeto, apesar das regras serem transparentes (a oferta ter de ser paga e o retorno egoísta ser esperado) o que se dá é um voto de confiança, a certeza é sempre presumida, cria-se a máxima: "confiar totalmente ou desconfiar totalmente', eis a solução" proposta por Mauss no Ensaio sobre a dádiva e definido por Caillé (1998:11) como o terceiro paradigma. Acerca disso, este autor retoma o termo gift de Mauss para exemplificar que na dádiva há a mesma proposta do pharmakos: o remédio e o veneno são dádivas obrigatórias àqueles que dão (morador local) e àqueles que recebem (por exemplo, a Matinta Perera), pois quem "quer o dom, acrescenta Godbout (1992:15), quer o veneno": o donatário que aceita a dádiva, aceita as regras de retribuição.

A dádiva é, segundo ele [Mauss], indissociavelmente "livre e obrigada" de um lado, e interessada e desinteressada do outro. Obrigada, pois não se dá qualquer coisa a qualquer pessoa, num momento qualquer ou de qualquer modo, sendo os momentos e as formas da dádiva, de fato, socialmente instituí- dos, como bem nota o holismo (Caillé 1998:12).

Não caberia essa mesma definição para o sacrifício cunhado por Mauss e $\mathrm{Hu}-$ bert antes do Ensaio sobre a dádiva? Caillé (1998:12) diria que sim, conforme se trata de "um modelo de ação social totalmente diferente o que ele nos apresentava na reflexão acerca do sacrifício ou da dádiva". Contudo, o ato de dar e de receber ganha expressão somente quando fixados "numa certa atmosfera de espontaneidade. É preciso dar e retribuir. Sim, mas quando, quanto, e com que gestos, quais entonações?". Estes são questionamentos que localizam as situações e a prática de oferecer mediante os elementos que determinam o posicionamento dos actantes nesse jogo que são as relações de aliança dentro de uma comunidade, a relação de convizinhaça é a máxima entre os moradores, por isso, o objeto dado ser colocado a serviço dos laços, o donatário reforça as relações apertando o nó ao aceitar a oferta; nas anotações realizadas por Godbout (1992:15), o dom deve ser pensado como uma relação contínua e bilateral, como uma relação, sobretudo, entre sujeitos.

Mesmo que para Mauss (2003:187) os presentes sejam, a rigor, voluntários, eles se expressam "na verdade obrigatoriamente dados e retribuídos". O que Mauss (2003:188) diz claramente é que "nesse gesto que acompanha a transação, há somente ficção, formalismo e mentira social, e quando há, no fundo, obrigação e interesse econômico". Essas trocas não são apenas coisas materiais, as trocas, como foi dito, são de amabilidades, enquanto que as 
riquezas, compreendidas como os bens materiais em si que fisicamente estão presentes na oferta, acrescenta Caillé \& Graeber (2002:24), transitam nessas relações não como fator primeiro, mas na marginália.

\section{CONSIDERAÇÕES FINAIS}

Observamos que a dádiva no oferecimento à Matinta Perera se configura como uma aliança, no sentido largo do conceito de Mauss, uma aliança que, sobretudo, une "os ritos, os casamentos, a sucessão de bens, os vínculos de direito e de interesse, posições militares e sacerdotais, tudo é complementar e supõe a colaboração das duas metades da tribo", assim "as duas frátrias se mostram respeito" (Mauss 2003:191).

A partir da dádiva, pensamos o outro em sua inteireza, porque as diferenças são permitidas e respeitadas, também porque cada lado do "contrato" sobrevive em função do outro ou, pelo menos, fortalece um vínculo de dependência mútua por meio da troca, intercambiam-se entre si e com os mitos.

O que não se quer é a anulação do consubstancial, buscam-se o elemento de contato para, a partir dele, manterem-se distantes. Não haveria encontro com a Matinta caso ela não se apresentasse como diferente: quem negaria a companhia da Matinta Perera nos caminhos sombrios das madrugadas de Taperaçu Campo ou na insegurança das marés quando a retribuição dessa companhia fosse apenas o café ou o peixe na manhã seguinte?
Se a solidão é contrária à sociedade, aceitar os termos do encontro com a divindade é reificar que a relação com os vizinhos é essencial para a manutenção da liga social na comunidade, sendo assim, o café, o tabaco e o peixe alimentam as matintas, na mesma proporção em que alimentam as relações sociais, apertando o nó que enlaça todos em Taperaçu Campo.

\section{NOTAS}

${ }^{1}$ Trabalho orientado pelo Dr. José Guilherme dos Santos Fernandes.

${ }^{2}$ Utilizamos o termo bruxa por conta das leituras do trabalho de Josebel Akel Fares $(1997,2007)$ e, posteriormente, Silva Júnior (2014). Não pretendemos inferir um pensamento colonizador a partir dessa expressão, apenas estamos considerando os estudos anteriores acerca deste mito que também se vale da outra expressão "a mulher do pássaro da noite" (Villacorta 2000).

${ }^{3}$ Reconheço os momentos em que fomos recebidos no quintal com barulhos adjacentes, em pátios com televisores ligados ou próximos ao trânsito de carros e motos e, ainda, com pessoas conversando em cômodos onde eu era recebido, que dificultaram pequenas partes das transcrições.

${ }^{4}$ Amigo morador da comunidade do Rio Ubim que me apresentou alguns conhecidos e familiares que poderiam contribuir para a minha pesquisa.

${ }^{5}$ As olarias em Taperaçu Campo são gerenciadas por famílias, as de pequeno porte, e por empresas, duas de grande porte.

${ }^{6}$ Utilizamos os termos divindade e entidade neste trabalho apenas para caracterizar os seres que estão além do plano humano, ou seja, os sobrenaturais, como o caso da 
matintaperera, da curupira, da mãe d'água etc.

${ }^{7}$ A compreensão de sacrifício (Mauss \& Hubert 2005:15) "sugere imediatamente a ideia de consagração" isso porque "em todo sacrifício um objeto passa do domínio comum ao domínio religioso - ele é consagrado”. Essa primeira observação de Mauss e Hubert é muito cara para a nossa pesquisa, pois a consagração se revela justamente na oferta que uma pessoa de Taperaçu Campo realiza em nome da divindade amazônica. Caillé (2002:180) em sua "antropologia do dom" explica em nota que tanto etimologicamente quanto literalmente "o termo sacrifício implica a idéia de um bem sensível oferecido ou destruído em honra de um ser superior" (grifo do autor) que além "de atestar a sua soberania" serve de igual modo "para obter dele proteção, perdão ou graça”. É dentro destes limites conceituais que aproximamos o oferecimento à Matinta perera de Taperaçu Campo ao conceito antropológico de sacrifício.

${ }^{8}$ Considerando-se aqui o barulho emitido pela Matinta Perera na forma ornitomórfica.

${ }^{9}$ Hoje em dia encontramos muitas casas de alvenaria na comunidade por conta da Resex e da olaria comunitária.

${ }^{10}$ Popularmente conhecida como telha de Brasilit.

\section{ENTREVISTAS}

Arlindo Araújo. Aposentado. 64 anos. Entrevista concedida a Fernando Alves da Silva Júnior. Taperaçu Campo, Bragança-PA, 2013. Gravação digital 56"38' estéreo.

Maria Silva Aviz. Aposentada. Entrevista concedida a Fernando Alves da Silva Júnior. Taperaçu Campo, Bragança-PA, 16 set. 2012. Gravação digital 48"57’ estéreo.
Maria Silva Aviz. Aposentada. Entrevista concedida a Fernando Alves da Silva Júnior. Taperaçu Campo, Bragança-PA, 19 mai. 2012. Gravação digital 1h44" estéreo. Raimundo Silva de Aviz. Aposentado. 65 anos; SOUSA, Agostinho da Silva. Aposentado. 69 anos. Entrevista concedida a Fernando Alves da SILVA JÚNIIOR. Taperaçu Campo, Bragança-PA, 16 set. 2012. Gravação digital 25"24' estéreo.

Aldenor Cirilo. Aposentado. Entrevista concedida a Fernando Alves da Silva Júnior. Taperaçu Campo, Bragança-PA, 30 dez. 2012. Gravação digital 17” estéreo.

Egídio Ferreira da Silva. Lavrador e presidente de associação comunitária. 62 anos. Entrevista concedida a Fernando Alves da Silva Júnior. Taperaçu Campo, Bragança-PA, 20 jul. 2013. Gravação digital 55'25' estéreo.

Orivaldo Pereira da Silva. Aposentado. 55 anos. Entrevista concedida a Fernando Alves da Silva Júnior. Taperaçu Campo, Bragança-PA, 12 abr. 2013. Gravação digital 2h24"29' estéreo.

Enedina de Sousa. Aposentada. 72 anos. Entrevista concedida a Fernando Alves da Silva Júnior. Taperaçu Campo, Bragança-PA, 12 jan. 2013. Gravação digital 7” estéreo.

João Coelho de Sousa. Aposentado. 73 anos. Entrevista concedida a Fernando Alves da Silva Júnior. Taperaçu Campo, Bragança-PA, 12 jan. 2013. Gravação digital 1h19" estéreo.

\section{REFERÊNCIAS}

Alberti, V. 2005. Manual de história oral. Rio de Janeiro: FGV.

Caillé, A. 1998. Nem holismo nem individualismo metodológicos: Marcel Mauss e o paradigma da dádiva. Rev. bras. Ci. Soc. 
13(38):5-38. Disponível em http://www. scielo.br/pdf/rbcsoc/v13n38/38caille. pdf

2002. Antropologia do dom: o terceiro paradigma. Petrópolis: Vozes.

Caillé, A., \& D. Graeber. 2002. Introdução, in $A$ dádiva entre os modernos. Organizado por P.H. Martins, pp. 17-31. Petrópolis: Vozes.

Cascudo, L.C. 1978. Literatura oral no Brasil. Rio de Janeiro: José Olympio.

Fares, J.A. 1997. Imagens da mitopoética amazônica: um memorial das matintas pereras. Dissertação de Mestrado, Universidade Federal do Pará, Brasil.

2007. Imagens da matinta perera em contexto amazônico. Revista Boitatá (3):62-78. Disponível em http://www.uel. br/revistas/boitata/volume-3-2007/Artigo \%20Bel.pdf

Godbout, J. 1992. O espirito da dádiva. Lisboa: Instituto Piaget.

Lanna, M. 2000. Nota sobre Marcel Mauss e o Ensaio sobre a dádiva. Revista de sociologia e politica 14: 173-194. Disponível em http://www.scielo.br/pdf/rsocp/n14/ a10n14.pdf

Mauss, M. 2003. Ensaio sobre a dádiva, in Antropologia e sociologia. Editado por M. Mauss, pp. 183-314. São Paulo: Cosac Naify.

Mauss, M., \& H. Hubert. 2005. Sobre o sacrifício. São Paulo: Cosac Naify.

Silva Júnior, F. A. 2014. Representação Feminina no Mito da Matintaperera em Taperaç Campo, Bragança (PA). Dissertação de Mestrado. Programa de Pós-Graduação em Linguagens e Saberes na Amazônia, Universidade Federal do Pará, Bragança/ PA, Brasil.

Villacorta, G.M. 2000. "As Mulheres do Pássaro da Noite": pajelança e feitiçaria na região do salgado (Nordeste do Pará). Dissertação de Mestrado, Universidade Federal do Pará, Brasil.

Recebido em 01/03/2014

Aprovado em 29/07/2014 